REVIEW

\title{
Ethical and legal issues in research involving human subjects: do you want a piece of me?
}

M B Kapp

J Clin Pathol 2006;59:335-339. doi: 10.1136/jcp.2005.030957

The conduct of biomedical research involving the participation of human beings implicates a variety of ethical concerns pertaining to such values as dignity, bodily integrity, autonomy, and privacy. These ethical concerns have been translated into a complex regulatory apparatus in the USA, containing specific legal provisions concerning such matters as participant safety, informed consent, and confidentiality. A topic of particular interest for pathologists is the handling of human tissue specimens that may be used for present, or stored for future, research purposes. This article examines the ethical and legal ramifications of obtaining and storing tissue samples for research purposes, with special attention to the issues of informed consent and confidentiality.

Correspondence to: Marshall B Kapp, Garwin Distinguished Professor of Law and Medicine, School of Law, Southern Illinois University, 1150 Douglas Drive, Carbondale, IL 62901-6804, USA; kapp@siu.edu

Accepted for publication 18 January 2006
$\mathrm{T}$ he conduct of biomedical research involving human participants raises a host of ethical and legal issues that have concerned philosophers, lawyers, policy makers, scientists, and clinicians for many years. ${ }^{1}$ After briefly enumerating several relevant ethical principles and the legal apparatus that has been developed specifically in the USA to effectuate those principles, I will outline one matter of particular interest to pathologists: the obtaining and retention of human tissue samples for use in current or future research projects.

\section{UNDERLYING ETHICAL PRINCIPLES}

Biomedical research is conducted for the purpose of systematically collecting and analysing data drawn that may aid in improving the care of currently unknown beneficiaries in the future. ${ }^{2}$ The chief role of human participants in research is to serve as sources of needed data. This is a different situation than ordinarily occurs in clinical medicine, in which diagnostic or therapeutic interventions are suggested or carried out solely to benefit the current patient. ${ }^{3}$ Consequently, although many ethical issues overlap between the realms of research and clinical medicine, the ethics concerns in human subjects research are not identical to those arising in the diagnostic and therapeutic context.

The most salient ethical values implicated by the use of human participants in research are beneficence (doing good), non-maleficence (preventing or mitigating harm), fidelity and trust within the fiduciary investigator/participant relationship, personal dignity, and autonomy from which generalisable conclusions may be pertaining to both informed, voluntary, competent decision making and the privacy of personal information. ${ }^{4}$ These (as well as other) ethical concerns are addressed by an extensive regulatory structure pertaining to human subjects research. The historical and philosophical background culminating in the present American system of governmental command and control regulation in this arena has been extensively chronicled elsewhere. ${ }^{5}$

\section{GENERAL REGULATORY OVERSIGHT IN THE USA}

Based largely on the recommendations of the National Commission for the Protection of Human Subjects in Biomedical and Behavioral Research (the Belmont Commission), established by the 1974 National Research Act, American regulations governing the conduct of biomedical research involving human participants were published in 1981 by the federal Department of Health and Human Services (DHHS) (at that time, the Department of Health, Education and Welfare). Most US health care institutions conducting research have now agreed to apply these federal regulations to all of their research protocols regardless of the funding source for a particular study. Additionally, numerous other federal agencies have adopted the DHHS regulations, as subsequently amended, as a Common Rule to protect human participants in any research protocol that those agencies sponsor. ${ }^{6}$ Research involving the testing of investigational drugs or medical devices is regulated concurrently by the federal Food and Drug Administration (FDA) ${ }^{7}$; the Common Rule and FDA requirements overlap considerably but are not completely identical.

Research to which the Common Rule or FDA regulations, or both, apply must be reviewed and approved initially by an institutional review board (IRB) recognised by the federal Office of Human Research Protections (OHRP) within the Office of the Secretary, DHHS. The research activity is then subject to continuing IRB oversight and at least annual reapproval thereafter. To approve (and renew approval for) a protocol, the IRB must determine that each of the following requirements is satisfied:

Abbreviations: AAMC, Association of American Medical Colleges; HIPAA, Health Insurance Portability and Accountability Act; IRB, institutional review board; OHRP, Office of Human Research Protections; PHI, protected health information 
- Physical and psychological risks to subjects are minimised.

- Physical and psychological risks to subjects are reasonable in relation to anticipated benefits to those subjects and to the importance of the general knowledge that may reasonably be expected to result.

- Selection of subjects is equitable

- Informed consent will be obtained, including at least the following items being communicated to potential participants or their authorised surrogates:

- purposes of the research, its expected duration, and the nature of any interventions/experiments;

- anticipated risks and benefits of participation and the reasonable alternatives to participation in the research protocol;

- confidentiality provisions relating to the research records;

- any compensation and/or treatment available for research related injuries;

- the right to not participate and to discontinue participation at any time without penalty.

- Informed consent will be documented appropriately.

The regulatory provisions for informed consent in research are basically a codification and extension of the American common law informed consent doctrine ${ }^{8}$ that was developed by the courts in the therapeutic setting.

As a complement to the federal regulation, some individual states have enacted statutes containing protections for human participants, requiring some type of prior review and oversight. ${ }^{9}$ The specific content of these state laws varies. Also, private civil lawsuits may be brought by a particular participant against researchers and protocol sponsors for breach of common law tort standards of care (that is, medical malpractice) in the conduct of research involving and harming that participant. ${ }^{10}$

\section{TISSUE SPECIMENS}

\section{Uses in research}

Hakimian and Korn" observed, "Human biological specimens have been the foundation of pathological inquiry ever since Rudolf Virchow propounded the cellular basis of disease in 1858. Today, the study of human tissue affords unique and increasingly sophisticated molecular and genetic insights that progressively illuminate the detailed mechanisms and pathways of human diseases."

Tissue specimens may be sought specifically for use in a current research protocol from individuals who are either undergoing non-experimental diagnostic or therapeutic interventions for a medical problem, or who are currently participating in a different research protocol. Also, with increasing frequency, patients or current research participants are being asked to donate bodily tissue for storage and possible use at some future date as part of human genetic studies whose precise details are not yet known or knowable. ${ }^{12}$ It has been noted that the genetic analysis of human tissue samples may result in highly useful information about genetic explanations of human disease. In the light of developments fuelled by the Human Genome Project, "both the number of known target genes and the methods for rapid and inexpensive genetic analysis are increasing, as is our realization of the complexity of the genetic links of common diseases." ${ }^{13}$ Research addressing complex diseases involving many different genes will require the study of tremendous amounts of data on both the genotypes and phenotypes of numerous people. Researchers both in the USA and internationally are looking enthusiastically at the creation of vast database resources to house the human tissues collected to supply this potentially valuable genetic material.

\section{The ethical and regulatory debate}

The collection of human tissue specimens for use in current, and especially in potential future, research protocols raises a panoply of ethical concerns about, among other things, consent and confidentiality. These ethical issues manifest themselves in a regulatory context. Debates about these issues have been carried out for a considerable time. ${ }^{14}$ More than a decade ago, the National Institutes of Health and the Centers for Disease Control and Prevention jointly issued a Consensus Statement on "Informed Consent for Genetic Research on Stored Tissue Samples. ${ }^{\prime 15}$ In August of 1999, the National Bioethics Advisory Commission published a report that looked comprehensively at the uses of human biological materials and issued 23 recommendations generally trying to interpret the language of the existing Common Rule rather than replace it. ${ }^{16}$

\section{Informed consent}

When a person is having tissue removed (with their consent) as part of a treatment intervention and is asked for permission to allow a piece of that tissue to also be available for use in a related ongoing genetic study, valid consent for the additional research use would require that the participant be told clearly whether the genetic study is an integral part of the treatment protocol or is an entirely separate investigation. Only in the former situation could the investigator legitimately condition receipt of the treatment on the participant's agreement to have tissue analysed for research purposes. If the genetic study is separate, a volunteer may refuse to donate tissue to it without giving up the chance to participate in the treatment protocol.

Whether linked to present patient treatment or totally separate, a current research project can be described to a prospective tissue donor with enough precision to allow for meaningful informed consent. By contrast, it is difficult, if not impossible, for a participant in a research protocol to give meaningful prospective consent to the use of tissue in a possible future research protocol that cannot currently be described. Common practice has been for IRBs to allow investigators to ask patients receiving treatment to give a generic approval for the current banking of tissue, but only on the condition that use of the tissue in specific research protocols in the future would require an additional consent from the patient, based on specific information conveyed about the particular genetic study at that later point in time.

Recent events have fuelled the controversy over the ethical and legal need to obtain a tissue donor's informed consent for the collection, storage, and use of the donor's biological specimen for research purposes. In an August 2004 guidance document, the federal OHRP sought to clarify its position regarding consent requirements when human biological specimens are used in research by "reaffirm[ing] OHRP policy (see OHRP guidance on repository activities and research on human embryonic stem cells) that, under certain limited conditions, research involving only coded private information or specimens is not human subjects research." (emphasis in original) ${ }^{17}$ Under this guidance, tissue collection for present or future research purposes is not subject to the IRB review and informed consent provisions of the Common Rule, as long as there is no personally identifiable information attached to the tissue specimens. The OHRP guidance "recommends that institutions have policies in place that designate the individual or entity authorized to determine whether research involving coded private information or specimens constitutes human subjects research." 
Some confusion remains, however, because, despite OHRP's interpretation exempting collection of non-identifiable tissue specimens from application of the Common Rule, FDA regulations mandating the obtaining of informed consent for the collection and use of tissue specimens in present or future research protocols involving the testing of investigational drugs or medical devices still do apply with full force. This disharmony in regulatory requirements has been noted critically by commentators ${ }^{18}$ and groups representing biomedical investigators. ${ }^{19}$ In a letter to OHRP dated 11 January 2006, the Association of American Medical Colleges observed: "Discordant guidance from different agencies puts institutions in an untenable position and creates confusion and anxiety where none should exist." ${ }^{20}$ The problem results because the FDA regulatory definition of human subject differs from the definition of human subject under the Common Rule, with the former including within the definition the use of unidentified tissue specimens.

It is noteworthy that, in recognition of the disruptiveness of the Common Rule/FDA regulatory disharmony on this point, the FDA had published, ${ }^{21}$ two days before the date of the AAMC letter, a public notice that it is in the process of preparing a new guidance document to be entitled "Guidance on informed consent for in vitro diagnostic device studies using leftover human specimens that are not individually identifiable." The regulations themselves would remain intact. However, FDA indicated in its 9 January 2006 Federal Register publication an intent to notify the public, through the issuance of a guidance document, that FDA will "exercise enforcement discretion [that is, refrain from enforcing the regulations] as to the informed consent regulations for clinical investigators, sponsors, and IRBs" when:

- the study uses leftover specimens; that is, remnants of specimens collected for routine clinical care or analysis that would have been discarded if not used in the study;

- the specimens provided to the investigator are accompanied by only minimal clinical information such as age, sex, and existing laboratory results;

- the specimens are not individually identifiable;

- the specimens are provided to the investigator(s) without identifiers and the supplier of the specimens has established policies and procedures to prevent the release of personal information;

- the individuals caring for the patients are different from, and do not share information with, those conducting the investigation; and

- the study has been reviewed by an IRB.

The August 2004 OHRP guidance on this subject has been characterised by at least a few commentators not (as OHRP explicitly claims) as merely a reaffirmation of existing policy, but instead as "a dramatic shift" leaving "an enormous regulatory gap in which, with a minimum of effort, the majority of research involving databanks can be excluded from the Common Rule." ${ }^{22}$ One argument in favour of imposing substantial affirmative informed consent requirements rather than allowing exemption altogether or substituting presumed consent (with an opportunity to object) would focus on the risks involved in donating tissue. This argument is exemplified by the comment, "In human tissue research, genomic technology has not only increased the demand for human tissue, but it has also increased the potential for tissue donors to be subjected to both psychosocial and economic harms." ${ }^{23}$

However, most arguments supporting a specific consent requirement for present or future research uses of human tissue specimens, even if anonymised, rest more on the claim that basic personal interests are at stake for the prospective tissue donor. This is the contention: "There should be no doubt about what is at stake in developing policy for the use of stored samples: the fundamental right to decide whether and how one's body and its parts will be used in research." 24 As explained by a proponent of requiring informed consent for the conduct of research using non-identified tissue specimens: "Informed consent is not just about enabling people to decide whether or not to accept certain risks. Seeking permission to use biobanks can be valuable for its own sake as well. The process of asking acknowledges the individual whose information and tissue are obtained therein. In the case of research, informed consent is one part of honoring the contribution that the person is making to advancement of knowledge."25

Regulatory proponents additionally cite evidence that at least a significant minority of patients polled want to be informed in advance and afforded the opportunity to consent to or refuse the use of their tissue for research purposes. ${ }^{26}$ This desire bolsters the argument that the storage and use of tissue specimens in research protocols is a matter about which people really care and, therefore, strongly want their autonomy rights respected..$^{25}$

This part of the proponents' argument is weakened, though, by a number of study findings to the contrary. For instance, some studies of tissue donors' preferences and perceptions have been interpreted to show that most patients do not share professional bioethicists' concern about the potential research related uses of their surplus tissues. Responses to one questionnaire revealed that "only a small number [of patients supplying tissue specimens] report their information levels to be of particular importance when biobank based research is assessed in relation to other issues pertaining to research politics and ethics...This study calls for reconsideration of the importance attributed to informed consent in debates about ethics of biobanks and genomics companies..."27

Other surveys demonstrate that most individuals who have had tissue removed for other purposes have no objection to the unlimited use of excess tissue in future research studies. These findings-as well as the position that the law appears not to recognise donors' personal ownership rights pertaining to surplus tissue specimens taken from those individuals for diagnostic or therapeutic purposes ${ }^{11}$ - underpin the contention by some that a patient's valid consent for future research uses of previously collected tissue specimens should be made on the basis of a binary choice (either authorising all future research uses or none at all) rather than requiring investigators in every new research protocol to track down and obtain specific consent from every tissue donor, even if the specimen is identified only by a code. ${ }^{28}$ Other bioethics scholars go further, arguing that the "data [regarding what matters actually are important to patients] suggest applying a tentative general framework for obtaining consent for research using stored biological samples. Consent should be required for research using clinically derived, identified samples, but waived for additional research using research derived, anonymized samples." ${ }^{29}$

An active ethical/social policy discussion about the parameters of informed consent for research uses of surplus human tissue specimens undoubtedly will persist in the USA for the foreseeable future, as we delve ever further into the genomic era of biomedical progress. For the time being, the regulatory approach to this question has been resolved by OHRP and FDA in the respective manners described above. Whether the present approach of OHRP to exclude the research use of coded tissue specimens from the classification of human subjects research, subject to the requirements of the Common Rule, constitutes a serious gap in legal protection for vulnerable individuals, or whether a realistic 
recognition that the ability to give or withhold informed consent in this context is not an especially important value to most potential tissue donors remains to be seen.

Policy makers in the USA also should closely monitor the legal and ethical approaches of the international community to the informed consent question in this context. In the United Kingdom, the well publicised Alder Hey and Bristol Royal Infirmary inquiries, revealing systematic retention of postmortem organs from children for educational and research purposes, without obtaining authorised informed consent, engendered substantial debate about the role of informed consent in research related tissue specimen collection. ${ }^{12}{ }^{30}{ }^{31}$ Various informative surveys of relevant public and professional attitudes have been conducted in Europe ${ }^{26} 32$ and Asia. ${ }^{33}$ Pertinent laws and customs have been developed in different countries to address this matter, accompanied by various degrees of controversy about how they balance patients' rights and society's interest in having research conducted. ${ }^{34}$ Inconsistent national laws contribute to confusion and inhibit collaborative research efforts, ${ }^{35}$ but conflicting ethical, cultural, and religious perspectives will continue to make international regulatory harmonisation a highly difficult challenge. ${ }^{36}$

\section{Medical privacy requirements}

Because possible unfair discrimination against an individual by a present or potential employer, insurer, educator, or other party on the basis of genetic information derived from a scientific analysis of the individual's tissue specimen is a major risk of allowing one's tissue to be available for research purposes, it is necessary to consider the confidentiality implications of collecting and storing tissue to be used in the research context. In the USA, medical confidentiality rules derive from, and may be enforced under, common law tort doctrine and any applicable state statutes and regulations. However, the chief American source of pertinent legal authority is the federal Standards for Privacy of Individually Identifiable Health Information (Privacy Rule). ${ }^{37}$ This regulation became effective in 2003 after being promulgated by DHHS under the legislative authority of the Health Insurance Portability and Accountability Act (HIPAA). ${ }^{38}$

The Privacy Rule requires specific written permission from a patient before anyone may use or disclose "protected health information" (PHI) about that person for non-routine purposes such as research. PHI is defined as any "individually identifiable health information" transmitted or maintained by a "covered entity" (for example, a health care provider, health insurance plan, or data processing firm).

In the context of research using stored tissue specimens, the reach of the HIPAA Privacy Rule is somewhat constrained. First, tissue repositories such as biobanks are not "covered entities" subject to the Rule unless they conduct some other kind of activity that brings them within the "covered entity" definition. The Privacy Rule would be implicated only with regard to a covered entity, such as a hospital, that discloses PHI for the creation or stocking of the research repository. "It is the act of the health care provider sending a specimen to a commercial sponsor while knowing that it will be retained in a repository that triggers the HIPAA written authorisation form requirement, not the sponsor's actions in maintaining the repository." 40

Moreover, the Privacy Rule would only apply to a covered entity that sends to a repository tissue that is accompanied by clinical information containing specific patient identifiers. "The Privacy Rule permits covered entities to release data that have been de-identified without obtaining an Authorization and without further restrictions upon use or disclosure because de-identified data is not PHI and, therefore, not subject to the Privacy Rule." 39 "The Privacy Rule permits covered entities under the Rule to determine that health information is de-identified even if the health information has been assigned, and retains, a code or other means of record identification, provided that: (1) the code is not derived from or related to the information about the individual; (2) the code could not be translated to identify the individual; and (3) the covered entity under the Privacy Rule does not use or disclose the code for other purposes or disclose the mechanism for re-identification." ${ }^{17}$

\section{CONCLUSIONS}

Pathologists everywhere involved in various aspects of research involving human participants must be cognisant of the regulatory environment impacting their activities in their particular jurisdiction and the ethical principles underlying the applicable local legal rules. In this article I have outlined the salient boundaries of the regulatory environment for biomedical research. I have devoted particular attention to current approaches and controversies about informed consent and the ramifications of medical confidentiality when obtaining human tissue specimens for use in current research protocols or storing them for use in future protocols, the details of which cannot be predicted or described to the potential tissue donors.

\section{REFERENCES}

1 Coleman CH, Menikoff JA, Goldner JA, et al. The ethics and regulation of research with human subjects. Newark: Matthew Bender Co, 2005:3-50.

2 Code of Federal Regulations, Part 46.102(d).

3 Sankar P. Communication and miscommunication in informed consent to research. Med Anthropol Q 2004;18:429-46.

4 Veatch RM. The patient as partner: a theory of human experimentation ethics. Bloomington: Indiana University Press, 1987:16-76.

5 Jonsen AR. The birth of bioethics. New York: Oxford University Press, 1998: 125-65

6 Code of Federal Regulations, Part 46.

7 Code of Federal Regulations, Parts 50, 56, 312, and 812 .

8 Faden RR, Beauchamp TL. A history and theory of informed consent. New York: Oxford University Press, 1986:114-50.

9 Gibbs JN. State regulation of pharmaceutical clinical trials. Food Drug Law J 2004;59:265-85

10 Morreim EH. Litigation in clinical research: malpractice doctrines versus research realities. J Law Med Ethics 2004;32:474-84.

11 Hakimian R, Korn D. Ownership and use of tissue specimens for research. JAMA 2004;292:2500.

12 Savulescu J. No consent should be needed for using leftover body material for scientific purposes: against. BMJ 2002;325:649-51.

13 Greely HT. Breaking the stalemate: a prospective regulatory framework for unforseen research uses of human tissue samples and health information. Wake Forest Law Rev 1999;34:740.

14 Knoppers BM, Laberge CM. Research and stored tissues: persons as sources, samples as persons? JAMA 1995;274:1806-7.

15 Clayton EW, Steinberg KK, Khoury MJ, et al. Informed consent for genetic research on stored tissue samples. JAMA 1995;274:1786-92.

16 National Bioethics Advisory Commission. Research involving human biological materials: issues and policy guidance (1999), available at <www. bioethics.georgetown.edu/nbac $>$.

17 Office of Human Research Protection, United States Department of Health and Human Services. Guidance on research involving coded private information or biological specimens (August 10, 2004)..

18 Evans BJ, Meslin EM. Encouraging translational research through harmonization of FDA and Common Rule informed consent requirements for research with banked specimens. J Legal Med, (in press)..

19 Letter of Jordan J Cohen, President, Association of American Medical Colleges to Michael J O'Grady, Assistant Secretary for Planning and Evaluation, Department of Health and Human Services. Recommendations for regulatory reform, November 3, 2005.

20 Letter of Jordan J Cohen, President, Association of American Medical Colleges to Michael Carome, Associate Director for Regulatory Affairs, Office for Human Research Protections. Re: October 1, 2005 Draft Guidance on Reporting and Reviewing Adverse Events and Unanticipated Problems Involving Risks to Subjects or Others, January 11, 2006.

21 Federal Register. 71:1429 (January 9, 2006).

22 Clayton EW. So what are we going to do about research using clinical information and samples? IRB 2004;26:14-15.

23 Ashburn TT, Wilson SK, Eisenstein BI. Human tissue research in the genomic era of medicine: balancing individual and societal interests. Arch Intern Med 2000; 160:3377-84.

24 Sade RM. Research on stored biological samples is still research. Arch Intern Med 2002; 162:1439-40.

25 Clayton EW. Informed consent and biobanks. J Law Med Ethics 2005;33:15-21. 
26 Goodson ML, Vernon BG. A study of public opinion on the use of tissue samples from living subjects for clinical research. J Clin Pathol 2004;57:135-8.

27 Hoeyer K, Olofsson B-O, Miörndal T, et al. The ethics of research using biobanks: reason to question the importance attributed to informed consent. Arch Intern Med 2005; 165:97-100.

28 Chen DT, Rosenstein DL, Muthappan P, et al. Research with stored biological samples: what do research participants want? Arch Intern Med 2005; 165:652-5.

29 Wendler D, Emanuel E. The debate over research on stored biological samples: what do sources think? Arch Intern Med 2002; 162:1457-62.

30 Burton JL, Wells M. The Alder Hey affair: implications for pathology practice. J Clin Pathol 2001:54:820-3.

31 van Diest PJ. No consent should be needed for using leftover body material for scientific purposes: For. BMJ 2002;325:648-9.

32 Kettis-Lindblad A, Ring L, Viberth E, et al. Genetic research and donation of tissue samples to biobanks: What do potential sample donors in the Swedish general public think? Eur J Public Health Epub ahead of print, available at $<$ www.ncbi.nlm.nih.gov/entrez/query.fcgi?cmd> (October 5, 2005).
33 Ohnishi AA, Nishigaki E, Sekimoto $M$, et al. Attitudes of the Japanese public and doctors towards use of archived information and samples without informed consent: Preliminary findings based on focus group interviews. BMJ Med Ethics 2002;3:1 (published online).

34 Winickoff DE. Biosamples, genomics, and human rights: context and content of Iceland's Biobanks Act. J Biolaw Bus 2001;4:11-17. 35 Morente MM, Alonso S. Current challenges of human tumour banking.
Hematol Oncol 2005;23:54-56.

36 Maschke KJ, Murray TH. Ethical issues in tissue banking for research: the prospects and piffalls of setting international standards. Theor Med Bioethics 2004;25: 143-55.

37 Code of Federal Regulations Part 160 and Part 164, subparts A and E.

38 Annas GJ. Medical privacy and medical research - judging the new federal regulations. N Engl J Med 2002;346:216-20.

39 United States Department of Health and Human Resources. Research repositories, databases, and the HIPAA Privacy Rule, Available at <http:// privacyruleandresearch.nih.gov/research_repositories.asp > (posted January 12, 2004).

40 Allen MD. Commercial tissue repositories: HIPAA raises sponsors' fears. IRB 2004;26:9-10. 